\title{
Exemplary Goods: Exemplars as Judgment Devices
}

\author{
Erwin Dekker
}

\begin{abstract}
In this article the notion of exemplars is developed to study valuation processes. It argues that exemplary goods are an important 'judgment device' on markets of singular goods, which has so far been ignored in the literature. The article draws on Hannah Arendt's theory of exemplars, as well as literature from the philosophy of science and psychology to construct the new concept. Exemplars are particular goods that become focal points in markets that facilitate the mutual coordination of consumers and producers. From these exemplars norms of quality emerge which are otherwise hard or impossible to explicate. These exemplars and the norms of quality which emerge from them help shape the expectations of both producers and consumers with regard to new goods that are introduced to the market. Two illustrative cases, on classic literature and hip-hop music, are presented to demonstrate the relevance of the concept.
\end{abstract}

Key words: valuation; exemplars; economy of qualities; cultural economics; singular goods; classification

We frequently reason from particular to particular, from one unique instance to another. Lebron James is an excellent basketball player, but not as good as Michael Jordan. The recent Woody Allen movie is nice, but not as good as Annie Hall or Manhattan. Wealth inequality is almost as high as it was during the Belle Époque. This type of reasoning is important not just in everyday speech; but when we analyze business models the use of exemplary case studies is a recurring theme. We want our organization to run like the best out there. 'Harvard on the Maas' is the current aspiration here in Rotterdam. In science too, particular exemplars are important as an

Erwin Dekker, Erasmus School of History, Culture \& Communication, Erasmus University Rotterdam,e.dekker@eshcc.eur.nl

(C) 2016 Author

LiU Electronic Press, DOI 10.3384/VS. 2001-5992.1642103

http://valuationstudies.liu.se 


\section{Valuation Studies}

inspiration and guide to what good science is. Does an economist want to be an economist like Adam Smith or like Paul Samuelson? a sociologist like Max Weber or Talcott Parsons? This paper argues that exemplars are an important judgment device in markets for singular goods (Karpik 2010). These exemplary goods are not average examples, or representative of the wide variation out there, but they are able to capture the typical, the exemplary.

Market coordination is traditionally believed to occur via changes in prices and quantity. In a set of articles Hayek (1937, 1945) demonstrated that the power of markets is to coordinate a variety of individual economic plans via adjustments to market prices and quantities, a process which lies at the heart of supply-and-demand dynamics. Central to this process is the use of knowledge that is dispersed throughout society. Hayek, and economists after him, however, has largely neglected how quality coordination can occur. This project has recently been taken up by Lucien Karpik (2010). He argues that in markets for singular goods-goods which are all different from one another such as movies, medical services or dining experiences-such coordination via price and quantity is of limited importance. According to him quality coordination is, in line with Hayek, of great importance in such markets (see also White 2002). To study quality coordination Karpik develops four economic coordination regimes, which are institutional arrangements that structure the dispersion of knowledge in different markets for singular goods (Karpik 2010). Within these economic coordination regimes, he identifies different judgment devices, which act as signposts for consumers. Karpik broadly uses this notion to include advertising, reviews, rankings and networks. Sometimes these judgment devices are developed by producers or consumers, but often mediators are important actors in this coordination process. Without wishing to contest the importance of Karpik's judgment devices, we focus here on a different type of judgment device, the exemplary good. The exemplary good is (one of the) currently prominent goods, which acts as reference or focal point for the identification of the relevant qualities of a particular type of good for consumers.

To develop the concept of exemplars, and exemplary goods, we will build on Hannah Arendt's theory of judgment. Her theory is, like Karpik's, concerned with the tension between the general and the particular. Karpik calls these goods singularities, to emphasize their uniqueness, but he recognizes that to be understood they have to be related and commensurated to existing goods. Arendt argues that the exemplary mode of reasoning is of special importance when we judge the particular in light of the general, but without wanting to give up the uniqueness of the particular. This is typically the case for cultural goods as has been demonstrated in the various contributions of Nathalie Heinich (2005; for an English introduction see Danko 2008). 
So while products are unique, they are in fact compared, contrasted and related to these exemplars ("if you liked the West Wing TV-series, you will love the House of Cards"). This can lead to somewhat paradoxical claims, as we will see in one of the illustrative case studies of novels below ("a genius as singular as Robert Walser, Bruno Schulz or Joseph Roth"). We will demonstrate that the goods bought and sold in markets for singular goods often oscillate between the two poles of 'commodification and commensuration' on the one hand and 'singularization' on the other (Kopytoff 1986).

The second aspect of exemplars that we will highlight is the plural notion of quality they enable. In any category we will find multiple exemplars, which represent different particular instances of the good or the desirable. The traditional economic manner of studying the prices (and hence the valuation) of differentiated goods is to study the shadow prices of their individual characteristics. But, so argues Karpik, the characteristics of say a Bordeaux wine cannot be split up, its qualities are interdependent (Karpik 2010: 24-26). Splitting up a product into separable characteristics might work for airbags added to a car, but matters are not as simple for an added flavor element to a wine or an additional brushstroke to a painting. The fact that such goods can be good in multiple, interdependent dimensions and that these are interdependent is called multidimensionality by Karpik. But, while he recognizes that this leads to a wide variety of combinations that can be valued, his theory does not really allow us to deal with this plural notion of quality. The judgment devices which Karpik refers to, such as rankings or charts, ultimately presume a single notion of quality. This is different for the labels, appellations and signifiers that Karpik associates with the authenticity regime, but even they refer to somewhat broader categories with associated standards of quality. Exemplars on the other hand provide a way of maintaining a variety of quality "standards," through particular combinations of qualities, that more general judgment devices have trouble dealing with.

Finally exemplars are used across different economic coordination regimes. They serve an important role as reference points in graded category structures. The gradedness of categories means that some examples of a species or kind are a better example of that category than others. A robin is a more typical bird than the penguin or the ostrich. Exemplary goods are typically identified, precisely because they are a very good (or the best) fit. They embody a combination of qualities, which might be hard to make explicit, but which can be discovered through the interpretation of these exemplary goods.

Arendt's theory, as well as other contributions to thinking about exemplars, will be discussed in Section 1. In Section 2 we will develop the notion of exemplars as a judgment device. Sections 3 and 4 contain illustrative case studies, or vignettes, which demonstrate the empirical 


\section{Valuation Studies}

usefulness of this concept. Section 5 concludes with suggestions for further work in this direction.

\section{Exemplary Validity}

Although exemplars have a long tradition, for example in the Christian tradition of portraying the life of saints as exemplary lives, they have received little systematic attention in the study of valuation. The exception is Hannah Arendt's theory of judgment, in which exemplars occupy a prominent place. Arendt's magnum opus was to be a two-volume work on the life of the mind. The theory of judging-in which she develops the theory of exemplary validity-followed the two other aspects of the life of the mind: thinking and willing. Judging would come closest to the vita activa, of which Arendt originally believed judging to be a part. Arendt (1982: 76) argues in the lectures on Kant's philosophy that the specific difficulty of judging is: "the faculty of thinking the particular." Pure thinking for Arendt is thinking in the general, it is thinking in rules, laws and regularities. Judging on the other hand is to consider the particular in light of the universal, but to keep in mind the uniqueness of the particular. This difficulty is even greater when, and here she quotes Kant: "the particular be given for which the general has to be found." So she argues that if we are dealing with unique occurrences, such as in history, we have to consider those occurrences in light of the general, but keeping in mind that individual occurrences can never be completely subsumed under any generality. There are also a great many cases for which a generality has not yet been found, and in that case we can, by definition, only compare certain particulars to other particulars.

The type of reasoning called for in such cases is different from two well-known other modes of reasoning. The deductive mode of reasoning starts from a universal law and then deduces what is true of the particular as in the time tested: All men are mortal, Socrates is a man, and therefore Socrates is mortal. The other type of reasoning, prominent in the social sciences, is inferential reasoning which observes many particulars to arrive at "empirical regularities" which at some stage would preferably be formulated as universal laws. Inferential reasoning has been perfected with the development of statistics over the past century and a half or so and deductive reasoning has been perfected with the help of axiomatic mathematical reasoning, but exemplary reasoning is usually discarded as "mere anecdotal evidence."

The exemplary mode of reasoning is explained by Hannah Arendt by way of a table. One could have in mind a list of characteristics to which every table must conform to qualify as a table. If we then meet an object we can determine whether it fits the requirements: a flat top surface placed on a number of legs, etc. (deduction). Second, one could compare this particular object to the many tables one has seen in one's 
life, and by inferential judgment decide whether this too is a table. Or, Arendt (1982: 77) argues, one could "think of some table as the example of how tables actually should be: the exemplary table. This exemplar is and remains a particular that in its very particularity reveals the generality that otherwise could not be defined."

Exemplary reasoning allows us to maintain both the singularity and the generality. Through exemplars we get to know the qualities or the characteristics that exemplify what it means to be beautiful or moving. Or as Arendt (1982) puts it: "The example is the particular that contains in itself, or is supposed to contain, a concept or general rule [...] If we say of somebody that he is good, we have in the back of our minds the example of Saint Francis or Jesus of Nazareth." She could have added that it is frequently very difficult to make explicit what the general rule is that is "contained" in these exemplars.

Arendt adds another important insight to her theory. Exemplars, she argues, can only take on this meaning of exemplifying the good or the courageous when they are widely known within a particular community. This is in fact what she argues about Napoleon Bonaparte:

In the context of French history I can talk about Napoleon Bonaparte as a particular man; but the moment I speak about Bonapartism I have made an example of him. The validity of this example will be restricted to those who possess the particular experience of Napoleon, either as his contemporaries or as the heirs to this particular historical tradition. (Arendt 1982: 84-85)

The historical episode of the rule of Napoleon Bonaparte thus comes to stand for something more general, which nonetheless is hard to describe or define in the abstract or the general. Arendt argues that most concepts in the historical and political sciences-should we add the social?-have an exemplary nature, they cannot be exhaustively defined or delimited, but they derive their meaning from specific examples, or exemplars.

At this point of her theory Arendt comes close to Weber's theory of ideal types. By shifting from Napoleon Bonaparte as a particular ruler to Bonapartism as an idealized type of rule, Arendt, in, Weber's language, accentuates some typical features. As Weber argues: "we construct the concept 'city economy' not as an average of the economic structures actually existing in all the cities observed but as an idealtype" (Weber 1904 [1949]: 90). By doing so we create an "ideal" or a "mental image," that is not actually observed. That is not, however, how we will use the notion of exemplar in this article; for us it remains an actual and particular instance-although the act of interpretation of this instance will highlight certain features of that particular instance.

The emphasis on the particular is also what we find in the psychological literature on exemplars. In psychology the notion of exemplars has been used to study the cognitive formation of categories 


\section{Valuation Studies}

and thus links up directly with Arendt's emphasis on learning about characteristics of concepts (Mervis and Rosch 1981). The original contributions on this subject emphasize the heuristic nature of exemplars, which minimize cognitive effort and maximize cognitive content (Rosch 1978).

One of the most robust and important findings in this literature is that categories have a graded structure (Barsalou 1985). ${ }^{1}$ That means that not every member is an equally good example of a particular category. Some instances or examples are considered typical or exemplary of a category. A typical example of this finding is that that "robins" are consistently considered to be exemplary birds, but penguins far less so. Such exemplars are learned faster by children, and play a crucial role in category formation (Lynch et al. 2000). Typically it is believed that exemplars possess this function because they represent a "central tendency." But more recent studies have distinguished between a typical (central) instance and an exemplary instance. These sometimes overlap, but particularly when a notion of goodness is involved the exemplary tends to be close to some ideal, and thus far from the typical (Burnett et al. 2005). This finding will be of particular relevance in our consideration of the qualities of cultural goods in the next section. These studies further demonstrate that exemplars are more likely to be close to some ideal when expertise is involved, another issue of particular relevance for cultural goods.

The emphasis on learning and tacit knowledge in Arendt's account of exemplars is also present in Thomas Kuhn's writings on the subject. Kuhn discusses exemplars as having great importance in learning what a paradigm consists of. He argues that exemplars are of crucial importance for understanding in science, and he suggests that through the use of exemplars we learn knowledge that can frequently not be reduced to explicit general rules (Kuhn 1970: 194). While Arendt's analysis restricts itself to the human sciences, Kuhn makes clear that exemplars are equally important for understanding in the natural sciences.

\section{Exemplars as Judgment Devices}

The importance of classification and qualification have long been recognized by economic sociologists as being central to the valuation of goods (DiMaggio 1987). Michel Callon and colleagues (Callon et al. 2002: 199) in their work on "the economy of qualities" argue, for example, that: "All quality is obtained at the end of a process of qualification, and all qualification aims to establish a constellation of characteristics which are attached to the product and transform it temporarily into a tradable good in the market." But sometimes such

1 Some of the early authors on exemplars noted the connection with family resemblances as described by Wittgenstein (Rosch and Mervis 1975). 
qualification is difficult, or the categories are graded in complex ways; in such cases qualification is ambiguous or only a first step in the evaluation of quality. In such cases other judgment devices are likely to emerge (Musselin and Paradeise 2005: 93).

Particularly in markets for singular goods, that is, goods which are all unique in non-trivial ways, we expect a variety of judgment devices to emerge, to facilitate the process of valuation. Such markets are characterized by an "infinite variety" of goods, such as books or movies (Caves 2000: 6). For these types of goods what constitutes quality is almost without exception contested. Some goods are particulars for which the general still has to be found, to use the Kantian expression. Even if generalities are found, e.g. when we believe that character development is important for novels, how much or what type of character development we would like to see is contested. More importantly still, efforts to explicate what would count and what would not count as character development are bound to fail due to the open-ended character of such concepts. Third, as Karpik notes, the qualities of these goods are interdependent so great character development in an otherwise failed novel will be of little value. This is where exemplars are important; they provide particular instances in which we find the quality of character development, in combination with other qualities, "in action" or "exemplified."

The notion of judgment devices emphasizes processes of coordination. Producers and consumers do not naturally exchange or find each other. Markets for singular goods, as well as many more standardized goods, are full of mediators, middlemen, judgment devices and norms which facilitate this exchange. Exemplary goods are one example of this mediating process. Traditional economic models pay little attention to this process of coordination and mediation. But in the Austrian tradition, of which Hayek is the most important exponent, processes of coordination are always center stage and the relevant knowledge has to be discovered. This is true for prices, which allow market calculation to take place, but also true for judgment, or what Hayek calls the knowledge of time and place (Hayek 1945). This means that for him an essential part of the competitive market process is the discovery and use of knowledge: "Competition is essentially a process of the formation of opinion: by spreading information, it creates that unity and coherence of the economic system which we presuppose when we think of it as one market" (Hayek 1948: 106). It is at this point that the economic sociology of Callon and Karpik meets the economics of Hayek.

Existing exemplary goods allow us to interpret new goods that come on the market. It is in this sense that exemplars help coordinate markets. Meaning is a category frequently neglected-or should we say taken for granted-in economic theorizing, but exemplars and their accepted interpretations are guides for interpretation of new 


\section{Valuation Studies}

goods. In the cultural economic as well as the broader economic literature the concepts of experience and credence goods have been developed, both of which stress the uncertainty associated with the consumption of differentiated goods. Traditional solutions to this issue stress the role of information, but not that of interpretation (and valuation). A recent paper by Earl and Potts (2013), however, goes some way to exploring the notion of consumption capabilities and the capacity to appreciate "newness" (see also Hutter 2011). Earl and Potts note the importance of previous points of reference, and the relation between new products and the existing set of consumption capabilities (which are an outcome of previous consumption). They, however, accept the information and pattern recognition framework that lies at the basis of modern microeconomic theory instead of emphasizing the importance of interpretation as emphasized in Arendt's theory of exemplary validity and Karpik's theory of judgment devices.

Arendt and Karpik both recognize that new goods (or situations) need be interpreted in relation to other particulars. There are no generally applicable rules and the (e)valuation of a new unique product is thus always an interpretive act, it requires judgment. In particular it requires a judgment about the commonalities it shares with other unique products, and thus also about what is a relevant comparison in the first place. We might easily agree that the Harry Potter novels are an outstanding success on the market, but to guide future action on markets they have to be interpreted. What makes these books successful? Which of their qualities are valued by consumers? Or in other words what is exemplary about these books?

Sometimes this judgment is rather passive on the side of the consumer, because as Barbara H. Smith (1983) observes in a different context: "Not only are the objects we encounter always to some extent pre-interpreted and pre-classified for us by our particular cultures and languages, but also pre-evaluated, bearing the marks and signs of their prior valuings and evaluations by our fellow creatures." How she continues is just as illuminating:

Indeed, pre-classification is itself a form of pre-evaluation, for the labels or category names under which we encounter objects not only, as was suggested earlier, foreground certain of their possible functions but also operate as signs - in effect, as culturally certified endorsements - of their more or less effective performance of those functions. (Smith 1983: 23)

In terms of exemplars, producers might guide the consumer with phrases like "from the makers of." Those pre-classifications, labels, category names and valuations are part of what Karpik calls judgment devices. 
In many other situations the judgment process will be more active, a point recognized by Karpik, in his distinction between four economic coordination regimes. In some regimes such as the mega-regime, most of the coordination is done before the product comes to market, and the agency of the consumer is limited. In other regimes there is more scope, or sometimes need, for interpretation by the consumer. The example of wines that Karpik (2010) studies in detail would be one example, where there is a combination of pre-classification and space for independent judgment by the consumer. Both Smith and Karpik, like many other scholars, are however primarily interested in the classification and qualification systems that exist one level above goods (see also Beckert and Musselin 2013). They are less attentive to the relations between goods, from one particular to the next.

It is even inherent in the definition of judgment devices that they are "tools to differentiate the quality of products" (Beckert 2012: 122). So strictly speaking one might argue exemplars cannot be such a "device" at all. But, if we think of particular categories, we soon realize that they are frequently defined by some exemplary good within that category. Think of recent products such as the tablet, or the smartphone, which have come to be defined by exemplary models. Or of categories which still bear the name of the first exemplary good. More importantly, we typically find that a shared intersubjective interpretation of exemplars will emerge, and as such they become something more general than just a particular good. Exemplars are literally a judgment device, in the sense that drafts, prototypes or other ideas for final products within design processes will typically be judged against current exemplary products. They also help shape expectations of consumers and suppliers alike, about what to expect in new products or what the chances of success for a new product are. Harrison White (2002: 79) describes what producers strive for: "each maneuvers to become sufficiently akin to other actors to become recognizable as their peer." But producers, as White points out, want to retain their individuality at the same time; the tension is very similar to that discussed above between maintaining individuality while being similar enough to be understood and recognized. That is why White talks about markets as networks. Within these networks exemplars can be thought of as the focal points.

In modern microeconomic theory we can find quite a few approaches in which the importance of such "focal points," industry standards, or dominant designs are discussed. One can think of exemplars as providing guidance in this world of infinite variety. The notion of focal points was developed within game theory, especially in the work on strategic interaction by Schelling (1960). Sugden (1995), who expands those ideas, suggests that focal points are helpful to individuals who seek to coordinate their behavior. They will rely on particular points of coordination which are "prominent" or "salient." 


\section{Valuation Studies}

But as Sugden acknowledges it is hard to incorporate labels or examples into game theory, which treats all strategies as formally identical (only distinguished by numbers such as strategy 1, 2, etc.). That is different for the examples that Schelling originally provided, such as the coordination problem of where to meet if you have agreed to meet in New York but have not agreed a specific place. That problem is a cultural coordination problem, whose answer depends on cultural conventions (at the station? in front of the town hall? in the main street?). Such solutions depend on what Schelling (1960: 57-70) calls a "degree of prominence or conspicuousness" or later the “obvious." Exemplars which gain prominence are precisely such prominent or obvious reference points.

We face a similar problem to that of coordinating on a meeting point, when we face the infinite variety of say novels or movies. It is therefore only to be expected that focal points emerge. Such focal points exemplify what a genre or subgenre is and they provide a shared starting point for conversations, interpretations and valuations of a genre ("if you want to see a science-fiction movie you should start with say ET, or 2001: A Space Odyssey or Star Wars”). More recently French economic sociologists who call their approach "economics of convention" have started to analyze how certain standards or conventions come to be established within markets or organizations. As explained by Levy (2002), in contrast to game theorists they do engage in the interpretation of conventions as they emerge within existing markets, and how such conventions shape reciprocal expectations about the behavior of others (see also Eymard-Duvernay et al. 2005). One of the central questions in this approach is how such conventions emerge and how they remain in place. One would expect that particular early examples of a good, early exemplars, help shape such conventions.

A final field in which exemplars have received attention is on the border between marketing and economics. Marketing scholars as well as economic sociologists have pointed to the importance of classifications and qualifications of goods. Some scholars have pointed to the importance of exemplars in the formation of new market categories (Rosa et al. 1999; Navis and Glynn 2010; Jones et al. 2012). Others have demonstrated that products or organizations that are difficult to classify or compare to an exemplar suffer an "illegitimacy discount," resulting in a lower valuation of the good (Zuckerman 1999; Carroll and Swaminathan 2000).

We will illustrate the role of exemplars as a judgment device with two cases-studies that are presented here not primarily for their inherent interest, but rather as illustrations of the empirical usefulness of the concept of exemplary goods. They demonstrate how we can operationalize the concept, and how it can help us understand the way in which exemplars become focal points, and shape the mutual coordination process between consumers and producers. 


\section{Marketing Forgotten Classics}

The magazine New York Review of Books (NYRB) has been publishing a series of books since 1999 under the label "NYRB Classics." The series, just as the magazine, is aimed at a serious readership, individuals who read widely and frequently, who know their way around the established literary canon, and who are interested in exploring world literature. The series primarily consists of books that have not previously been translated into English. The majority of the books was originally published in the twentieth century (85 percent) with another 10 percent of them from the nineteenth century (NYRB website). We have analyzed the extent to which exemplars are used in the descriptions of these 344 books provided on the website of the "NYRB Classics." This material consists of two parts: the description of the book as provided by the editor(s) of the classics series; and as a collection of typically three to five excerpts from reviews (by external parties) of the books.

One might argue that this material is far from neutral since it is meant to promote the book rather than to evaluate it. That is absolutely true. The material is not neutral, and the review excerpts are undoubtedly picked to make the book look good. However, this is not a problem for the purpose at hand, since the very reason for using exemplars is to coordinate the expectations of both the producers (the publisher in this case) and the consumers. The description provided on the website is a mixture of information about the book and praise for the book (a mix of the descriptive and the evaluative; see Kjellberg et al. (2013)). It is not unusual for publishers to request authors (or their agents) to position their manuscript in relation to other works on the market. As such the material is well suited to get insight into what sort of qualities are praised when considering this type of book.

The books in this series range in genre from novels to short stories and from science and history to essays and criticism. One would expect different exemplars to emerge within these genres, so we will restrict ourselves here primarily to novels and short stories, categories for which we have sufficient observations. An exemplar is counted as such when a book or an author in the NYRB series is compared or contrasted to a book or an author being described, or when he or she is mentioned as a literary heir to that author (for examples see below). What has not been included are famous reviewers (frequently themselves authors) who recommend the book and are included in the description (for example "Thomas Mann loved these stories").

The first thing we notice is the enormous variety of exemplars used in the total population of 344 books. No less than 339 exemplary authors or their works are mentioned to compare and contrast these books (out of these 108 are mentioned in at least two separate book descriptions). Aside from the comparison to other author's work we 


\section{Valuation Studies}

find references to works by the same author in 34 descriptions (10 percent). Another 44 descriptions (13 percent) contain references to the work of non-literary artists, ranging from Disney to Steven Spielberg, from Edward Hopper to Paul Klee, and from Beethoven to Miles Davis.

There are, however, also clear focal points, points of reference that are invoked more frequently than others. In Table 1 we have collected the authors that were mentioned at least five times in unique descriptions of books published in the series. It was necessary to exclude references to an author's own oeuvre, because some authors were published frequently in the NYRB Classics, notably Kingsley Amis, Georges Simenon and Patrick Leigh Fermor which would skew the results. Henry James is clearly the exemplary author. He is mentioned in 6.1 percent of the descriptions of novels and collections of short stories published in the series. Table 1 shows the results for the entire population of NYRB Classics as well as a more restricted population of novels and short stories only. The results show clearly that the great majority of references ( 90 percent) to these authors is made in the description of novels and short stories (the genres in which these authors, with the exception of Shakespeare, excelled).

\begin{tabular}{|l|r|r|r|r|}
\hline & All books & \multicolumn{3}{|c|}{ Novels and shorts only } \\
\hline Henry James & 16 & $5 \%$ & 15 & $6 \%$ \\
\hline Leo Tolstoy & 11 & $3 \%$ & 8 & $3 \%$ \\
\hline Charles Dickens & 10 & $3 \%$ & 9 & $4 \%$ \\
\hline Fyodor Dostoyevsky & 9 & $3 \%$ & 8 & $3 \%$ \\
\hline Anton Chekhov & 8 & $2 \%$ & 8 & $3 \%$ \\
\hline Franz Kafka & 8 & $2 \%$ & 8 & $3 \%$ \\
\hline Thomas Mann & 8 & $2 \%$ & 7 & $3 \%$ \\
\hline Vladimir Nabokov & 8 & $2 \%$ & 8 & $3 \%$ \\
\hline Patricia Highsmith & 7 & $2 \%$ & 7 & $3 \%$ \\
\hline James Joyce & 7 & $2 \%$ & 7 & $3 \%$ \\
\hline Gabriel Garcia Marquez & 6 & $2 \%$ & 6 & $3 \%$ \\
\hline Jane Austen & 5 & $2 \%$ & 4 & $2 \%$ \\
\hline Samuel Beckett & 5 & $2 \%$ & 5 & $2 \%$ \\
\hline Jorge Luis Borges & 5 & $2 \%$ & 5 & $2 \%$ \\
\hline Edgar Allan Poe & 5 & $2 \%$ & 5 & $2 \%$ \\
\hline Marcel Proust & 5 & $2 \%$ & 3 & $1 \%$ \\
\hline William Shakespeare & 5 & $2 \%$ & 4 & $2 \%$ \\
\hline Alexander Solzhenitsyn & 5 & $2 \%$ & 4 & $2 \%$ \\
\hline Mark Twain & 5 & $2 \%$ & 3 & $1 \%$ \\
\hline Evelyn Waugh & 5 & $2 \%$ & 5 & $2 \%$ \\
\hline
\end{tabular}

Table 1: Most mentioned authors in descriptions of separate books Note: The table lists the number of "mentions" and the percentages of descriptions in which they are mentioned. Source: author's own calculation 
From these basic findings we can start to ask more sophisticated questions. What are the determinants of the invocation of the exemplar? Are exemplars used when the cultural distance is large, or when it is smaller? Are female exemplars more frequently invoked for books by female authors? Our purpose here is merely to demonstrate the general importance of exemplars, but it should be clear that these illustrative results could easily be expanded.

One could also analyze the way in which these exemplars are used, which would lead to a more qualitative analysis. Do reviewers use exemplars to praise particular qualities, or do they instead compare books as a whole? Are exemplars primarily used to contrast or to compare? And what are the qualities which are associated with particular exemplars? Are there negative exemplars?

We will undertake a qualitative analysis in ection 4, but we will demonstrate here some of the ways in which these exemplars are used. As an example we will take the references to the work of Dostoyevski (eight in total). They are: "[Carpenter] surpasses even Gorki and Dostoyevski in depicting the despair"; "A Dostoyevskian tale of crime punishment, and the pursuit of ever-elusive redemption"; "Balzac's many literary inheritors from Dostoyevsky and Henry James to Marcel Proust"; "A handful of authors have portrayed the human condition of prison life with the indelible stamp of authenticity Dostoyevsky, Solzhenitsyn and Genet are among them"; "No one has written so well on prison life, since Dostoyevsky"; "Bernanos is, like Dostoyevsky, something of a sensualist of the soul"; "a sort of distaff Notes from the Underground"; "a lacerating exposition of the logic of identity that looks backward to Dostoyevsky, forward to Simenon." The final reference only comes across if we quote it more extensively:

These stories [by Krzhizhanovsky] represent strong entries in two different traditions of Russian literature: firstly, the unhinged, feverishly experimental universe [...] secondly, the grand woe of Dostoyevsky, in which is expressed the physic trauma of a frozen country so frequently torn asunder by ideology.

These references show that Dostoyevsky is not just referred to, but his work is actively engaged with by the descriptions and reviews. They highlight different qualities of his work: the authenticity, the depiction of prison life, the search for redemption, the exploration of identity and his analysis of ideology. In the final quote, the work of Dostoyevsky is referred to as something more general, like a tradition; it then becomes more than a particular.

To evaluate the quality of a book the reviewers and the description draw on an enormous register of qualities from a long-standing (western) tradition. The results in this small study are undoubtedly influenced by the vastness of the literary landscape and the fact that these descriptions are targeted at an insider audience. But there is no 


\section{Valuation Studies}

inherent reason to expect that expert-consumers in other fields are not able to handle such a multifaceted notion of quality as well.

The tension between commensurability and incommensurability, or commonalities and singularization, is repeatedly evident. Take for example the following two references. In the description of Gyula Krúdy's Sunflower the author is described as "a genius as singular as Robert Walser, Bruno Schulz or Joseph Roth," while J. G. Farrell's novel The Siege of Krishnapur is described in one of the review excerpts as "a masterpiece as unclassifiable as Guiseppe Lampedusa's novel 'The Leopard' or Penelope Fitzgerald's novel 'The Blue Flower.'” The singularity of these novels becomes a quality in and of itself it seems, and to emphasize this singularity, ironically, they are made commensurable to other highly original novels. Another striking example is to be found in the description of the later-to-be bestseller Stoner by John Williams which the review excerpt describes as: "an anti-Gatsby." Here the comparison is made to do two things at once; first contrast the allure of Fitzgerald's classic to the restraint of Stoner and second put the two books in the same league.

Exemplars are clearly used, by the editors of this series, to shape the expectations of potential consumers. They provide an accessible (at least for expert-consumers) interpretation of the qualities of the new good that is introduced to the market. The exemplars are reference points, and the new goods are positioned in relation to these focal points, and so the quality uncertainty associated with experience goods is reduced. This uncertainty is particularly present if there is no repeated consumption of the good as is the case in markets for singularities (although it is of course possible to read a novel multiple times).

What is less clear from this brief case study is the extent to which these "classics" are selected by the publisher for their relation to goods that are better known by their readership. It is not unimaginable that the selection process involves the positioning of these forgotten books in relation to better known exemplars and that the evaluation of them by the editors is based on their relation to these exemplars. This would be further evidence of the role of exemplars in the quality coordination process.

\section{The Making of a Classic Rap Album: Illmatic}

In this section we will focus on an argument put forward about what constitutes a classic hip-hop album. The debate about what makes a hip-hop album a classic flared up after the release of the widely acclaimed release of good kid, m.A.A.d. city by Kendrick Lamar. The album, to name but one of its many accolades, was voted best album of the year 2012 on the prestigious Pitchfork music website. Within the debate over the classic status of Lamar's new album a particularly cogent analysis was put forward by rap critic Andrew Nosnitsky 
(2012). He sums up his argument as follows: "When many people call good kid, m.A.A.d. city a classic, part of what they are unconsciously measuring is its Illmatic-ness."

Illmatic is the career-defining album of hip-hop artist Nas from 1994. The album is said to capture the sound of the gritty New York streets of the early 1990s with Nas's vivid metaphors and introspective lyrics over dark beats provided by some of the best hip-hop producers of the time. Illmatic has a playtime of just under 40 minutes and contains just ten songs-or nine if we exclude the intro-and is frequently praised for its cohesiveness. As Nosnitsky (2012) argues in his essay: "Nas does a few specific things almost perfectly on the record, while selectively sidestepping a lot of the other things that great rap songs and albums can do and have done." In other words Nosnitsky argues that Illmatic is in some ways an untypical hip-hop album.

Hip-hop, a genre that emerged in the late 1970s and early 1980s, was initially primarily party music. The early gatherings were street parties with electricity illegally tapped from the streetlights. The DJ was the main attraction, and the MC (who would later become the rapper) was secondary. Initially these DJs relied on specific parts of disco records (the breaks) but later also released their own songs. This meant that singles were much more important than albums. As Nosnitsky points out in his analysis, in the early 1980s when hip-hop came to the fore it was completely dominated by singles, and many of the major artists from that period never even released an album. That slowly changed during the 1980s when record labels were in search of saleable products and the message in the music became more important. When artists such as Run-DMC, Public Enemy and Boogie Down Productions started to release albums they consisted of the major singles (which had frequently been released before) while the rest of the album was filled with DJ songs or mega-mixes. That changed around 1990 when artists and groups consciously set about making cohesive albums that would live longer than the singles which typically disappeared after the radio stations stopped playing them.

Groups such as De La Soul and A Tribe Called Quest created albums that were clearly intended to be consumed as wholes, and that sometimes lacked more radio-friendly tracks that could be used as singles. As Nosnitsky (2012) argues about this trend:

This was apparent by the release of Nas' 1994 debut, Illmatic. If it wasn't the first classic-by-design, it was certainly the most visible (and probably still is). Nas was a highly-buzzed-about serious young rapper making a very serious rap album about his very serious world.

The standard by which hip-hop was valued started to change. The exemplary act was no longer the combination of a DJ with his MCs, 


\section{Valuation Studies}

but it was increasingly the individual rapper with a team of music producers behind him. This was visible in discussions about crucial terms such as the MC, the essence of which had been to "move the crowd" (emphasizing the live element) as one artist had famously proclaimed in the 1980s. In the 1990s the MC became the rapper, whose most important asset were his increasingly complex lyrics and flow-the term used to capture how rhythmically the rhymes are delivered-as recorded on record. Nas might be said to be the pinnacle of this development. The magazine The Source, which at the time of the release of Illmatic was the most respected magazine covering hiphop: "called it 'one of the best hip-hop albums I have ever heard' and gave it the magazine's perfect five mic rating." That same issue of the magazine contained an article which detailed the story of "the building a hip-hop classic" and which labelled Nas the second coming. During this process Illmatic slowly became the exemplar by which future hiphop albums came to be measured, or as Nosnitsky (2012) puts it: "The legend of Illmatic has snowballed in the years since, to where it's no longer just a rap classic, but the rap classic by which all rap classics are measured."

Illmatic became the exemplary hip-hop album. Seasoned hip-hop critic Elliot Wilson (2012) also appraises the Kendrick Lamar album by qualities associated with Illmatic: "it is a full body of work, not just a bunch of records thrown together." And there are similarities between the Kendrick Lamar album and Nas's classic album as Nosnitsky acknowledges: "heavy imagery, coming-of-age introspection." But Illmatic is a narrow exemplar to measure classic status by he argues: "Illmatic is almost never fun or funny, and it's generally more personal than political. It produced no major hits and today its songs don't exactly work as party starters in any room where listeners aren't already familiar with them." It is not that humor, politics and party music are not part of hip-hop-in fact the latter two more or less defined the genre during the 1980s-but that to be considered a classic an album should not contain too much of either. The argument by Nosnitsky is thus two-sided. On the one hand he shows what the exemplary validity of Illmatic has done for the subsequent reception of hip-hop albums, for how they are interpreted and valued. On the other hand he hopes to challenge this rather narrow standard by offering alternative exemplars: the party-oriented music of the early 1980s, the political music of the late eighties and the less cohesive and more ephemeral mix-tapes which came to dominate much of hip-hop in the internet-age.

Nosnitsky takes his argument one step further, beyond the reception of Kendrick Lamar's album. He extends his analysis to show how Illmatic has also served as the exemplary model of how to make a great hip-hop album. He argues that many hip-hop artists have increasingly left singles or more playful tracks off their album to better 
fit the standard set by Nas's classic album. The trend, as Nosnitsky (2012) argues, is most visible in the career of Jay-Z:

\begin{abstract}
His consensus Serious Rap Classics-Reasonable Doubt and The Blueprint-are definite classics-by-design, all relatively sensitive and somber and focused and 'honest', but they figure strangely into his catalog. Jay's a more adaptable rapper than Nas, so this sort of singularity doesn't necessarily suit him best. Certainly not from a commercial perspective-well-received but scattershot and singleoriented affairs like Vol. 3 [...] Life and Times of S. Carter or The Blueprint 3 have had far greater [commercial] success than his canonical classics.
\end{abstract}

The trend is also visible in repeated attempts by hip-hop artists to create classic albums by collaborating with one (or a few) producers to produce a cohesive album, rather than relying on a wide variety of producers and sounds, the more common approach.

That mold, if you like, fits certain artists better than others. To some it will feel like a constraint, and that is the effect of Illmatic that Nosnitsky emphasizes. There is another effect, however, because exemplars also help shape the production of future albums. In other words they enable as well as constrain artists wanting to make a (classic) hip-hop album. These constraints and possibilities are never absolute. Nosnitsky might be somewhat exaggerating the power of Illmatic as an exemplar, for no art (or entertainment) form is completely dominated by just one exemplar. Competing exemplars in hip-hop emerged regionally as for example in the albums of Dr. Dre which came to define the West-Coast sound and The Geto Boys, Outkast and UGK whose work would set the standard for the southern hip-hop sound. One could also think of the more recent singles-dominated albums by 50 Cent and Eminem, which maintained a balance between commercial success and critical acclaim. In that sense Kendrick Lamar's album, despite being from the West Coast, is indeed best compared with the example set by Nas. It shares the musical cohesiveness, the serious introspective content, and a lack of crossover singles with Nas's exemplary album.

Admittedly this study relies heavily on the analysis of one insightful critic, but from the considerations it nonetheless becomes clear what a qualitative study of exemplars might entail and the insights into the reception as well as the production of new products it might generate. The story of the emergence of Illmatic as a classic hip-hop album that comes to shape future productions also bears striking similarities with the emergence of the biopic genre in film, as described insightfully by Rick Altman (1999: 44). He demonstrates how a particular interpretation of a film, shaped by the reinterpretation of the exemplar after the release of subsequent films, comes to shape what a specific type of film is supposed to look like. Retrospectively this is called the biopic, but at the time of the initial success, it is far from clear, as Altman shows, what qualities of the film created its success. This line 


\section{Valuation Studies}

of reasoning is further corroborated by some of White's case studies (White 2002; see especially his discussion of Scottish knitwear).

\section{Discussion: Studying Exemplars in Markets}

In this article we have argued that exemplary goods are an important, yet overlooked, judgment device on markets. The paper offers a way to conceptualize exemplary goods, and demonstrates how the concept can be empirically operationalized to provide insight into the way in which meaning is coordinated on markets. The particular strength of exemplary goods as judgment devices lies in the way they are able to negotiate the tension between the general and the specific. Exemplars are particular goods, but they are interpreted to possess a combination of qualities which teaches us something about the desired qualities of a certain type of good. Other goods, perceived to be of the same type, are in turn compared, related and contrasted to these exemplary goods, which can be thought of as focal points for coordination on meaning and quality.

The illustrative case studies have highlighted important aspects of the use of exemplars. First, they demonstrate the coordination process in which current goods are positioned in relation to existing goods. Second, they demonstrate how the use of exemplars is important in advertising and critical discussion in the mediating process between consumers and producers. The case study of the marketing of books highlights how exemplars shape the expectations of consumers, and act as focal points in the communication between producer and consumer. The case study of the rap album demonstrates that particular important exemplars might significantly shape relevant notions of quality on a market or genre, and might hence influence the nature of later production. It also highlights the important mediating role of critics who interpret exemplars.

The case studies highlight moreover that the process of qualification and rating which has been made central in the valuation process of singular goods by Karpik and others misses important aspects. The use of exemplars does not rely on general categories or uniform ratings, but rather on the comparison of particulars. It does not rely on qualification within general categories, but rather on association or dissociation of particular goods. Exemplars moreover allow for a multiplicity of qualities in the valuation of singular goods, and do not rely on a single standard in the way that ratings do.

This article has not dealt with the way in which certain goods become exemplars, a question of great importance. It has simply assumed that there exist several or just one exemplary goods within a market. To develop the notion of exemplars further this should definitely be explored. Once certain goods are identified as exemplary they might shape the way in which markets develop, and create a certain path-dependency. 
The most important aspect economically is undoubtedly the study of how exemplars coexist and compete. That competition is a multifaceted process. Current incumbents might benefit from an intimate knowledge of the existing exemplars and how to interpret these. New entrants might be seeking to "break the mold" and attempt to establish alternative exemplars. Various exemplars however can exist next to one another, and shape the overall market structure or particular niche markets, as the illustrative case of the book series suggests.

Sociologically we might be interested in the way in which different intermediaries have the power to select and interpret the qualities of exemplary goods. Intermediaries as well as institutional and state actors might have power to select exemplary goods, or to (re)interpret exemplary goods in a particular way. But hopefully such concerns will not be separated from each other along older disciplinary lines, because they are all part of the way in which products are valued, and priced on markets.

Acknowledgments. I would like to thank the contributors to the Econ \& Culture seminar at the Eramus University of Rotterdam and two anonymous reviewers for their valuable suggestions; I am to blame for any error that remains.

\section{References}

Altman, Rick. 1999. Film/Genre. London: British Film Institute.

Arendt, Hannah. 1982. Lectures on Kant's Political Philosophy. Chicago, IL: University of Chicago Press.

Barsalou, Lawrence W. 1985. "Ideals, Central Tendency, and Frequency of Instantiation as Determinants of Graded Structure in Categories." Journal of Experimental Psychology 11(4): 629-654.

Beckert, Jens. 2012. "The 'Social Order of Markets' Approach: A Reply to Kurtulus Gemici." Theory and Society 41(1): 119-125, DOI 10.1007/ s11186-011-9160-6.

Beckert, Jens, and Christine Musselin. 2013. Constructing Quality: The Classification of Goods in Markets. Oxford: Oxford University Press, DOI 10.1017/CBO9781107415324.004.

Burnett, Russell C., Douglas L. Medin, Norbert O. Ross, and Sergey V. Blok. 2005. "Ideal Is Typical." Canadian Journal of Experimental Psychology 59(1): 3-10.

Callon, Michel, Cécile Méadel, and Vololona Rabeharisoa. 2002. "The Economy of Qualities." Economy and Society 31(2): 194-217. 


\section{Valuation Studies}

Carroll, Glenn R., and Anand Swaminathan. 2000. "Why the Microbrewery Movement? Organizational Dynamics of Resource Partitioning in the U.S. Brewing Industry." American Journal of Sociology 106(3): 715-762.

Caves, Richard. 2000. Creative Industries: Contracts between Art and Commerce. Cambridge, MA: Harvard University Press.

Danko, Dagmar. 2008. "Nathalie Heinich's Sociology of Art - and Sociology from Art." Cultural Sociology 2: 242-256, DOI 10.1177/ 1749975508091035.

DiMaggio, Paul. 1987. "Classification in Art." American Sociological Review 52(4): 440-455.

Earl, Peter E., and Jason Potts. 2013. "The Creative Instability Hypothesis." Journal of Cultural Economics 37(2): 153-173.

Eymard-Duvernay, François, Olivier Favereau, André Orléan, Robert Salais, and Laurent Thévenot. 2005. "Pluralist Integration in the Economic and Social Sciences: The Economy of Conventions." Post-Autistic Economics Review 34: 22-40.

Hayek, Friedrich A. 1937. "Economics and Knowledge." Economica 4(13): 33-54.

- 1945. "The Use of Knowledge in Society." The American Economic Review 35(4): 519-530.

- 1948. "The Meaning of Competition." In Individualism and Economic Order, 92-106. Chicago, IL: University of Chicago Press.

Heinich, Nathalie. 2005. L'élite artiste. Excellence et singularité en régime démocratique. Paris: Editions Gallimard.

Hutter, Michael. 2011. "Infinite Surprises: On the Stabilization of Value in the Creative Industries." In The Worth of Goods, edited by Jens Beckert and Patrik Aspers, 201-222. Oxford: Oxford University Press.

Jones, Candace, Massimo Maoret, Felipe G. Massa, and Silviya Svejenova. 2012. "Rebels with a Cause: Formation, Contestation, and Expansion of the De Novo Category 'Modern Architecture,' 1870-1975." Organization Science 23(6): 1523-1545, DOI 10.1287/orsc.1110.0701.

Karpik, Lucien. 2010. Valuing the Unique: The Economics of Singularities. Princeton, NJ: Princeton University Press.

Kjellberg, Hans, Alexandre Mallard, Diane-Laure Arjaliès, Patrik Aspers, Stefan Beljean, Alexandra Bidet, Alberto Corsin, Emmanuel Didier, Marion Fourcade, Susi Geiger, Klaus Hoeyer, Michèle Lamont, Donald MacKenzie, Bill Maurer, Jan Mouritsen, Ebba Sjögren, Kjell Tryggestad, François Vatin, and Steve Woolgar. 2013. "Valuation Studies? Our Collective Two Cents.” Valuation Studies 1 (1): 51-81, DOI 10.3384/vs. 2001-5992.13111.

Kopytoff, Igor. 1986. "The Cultural Biography of Things: Commoditization as a Process." In The Social Life of Things, edited by Arjun Appadurai, 64-91. Cambridge: Cambridge University Press.

Kuhn, Thomas S. 1970. "Postscript." In The Structure of Scientific Revolutions, 2nd ed. 174-210. Chicago, IL: University of Chicago Press. 
Levy, Thierry. 2002. "The Theory of Conventions and a New Theory of the Firm." In Intersubjectivity in Economics: Agents and Structures, edited by Edward Fullbrook, 254-272. London: Routledge.

Lynch, Elizabeth B., John D. Coley, and Douglas L. Medin. 2000. "Tall Is Typical: Central Tendency, Ideal Dimensions, and Graded Category Structure among Tree Experts and Novices.” Memory \& Cognition 28(1): 41-50.

Mervis, Carolyn B. and Eleanor Rosch. 1981. "Categorization of Natural Objects." Annual Review of Psychology 32: 89-115.

Musselin, Christine, and Catherine Paradeise. 2005. "Quality: A Debate." Sociologie Du Travail 47: 89-123, DOI 10.1016/j.soctra.2005.09.002.

Navis, Chad, and Mary Ann Glynn. 2010. "How New Market Categories Emerge: Temporal Dynamics of Legitimacy, Identity, and Entrepreneurship in Satellite Radio 1990-2005." Administrative Science Quarterly 55(3): 439-471.

Nosnitsky, Andrew. 2012. “Classic Material.” Pitchfork, http://pitchfork.com/ features/hall-of-game/8997-classic-material/, accessed June 8, 2016.

Rosa, José Antonio, Joseph F. Porac, Jelena Runser-Spanjol, and Michael S. Saxon. 1999. "Sociocognitive Dynamics in a Product Market." Journal of Marketing 63: 64-77.

Rosch, Eleanor. 1978. "Principles of Categorization." In Cognition and Categorization, edited by Eleanor Rosch and Barbara B. Lloyd, 27-48. Hillsdale, NJ: Lawrence Erlbaum Associates.

Rosch, Eleanor, and Carolyn B. Mervis. 1975. "Family Resemblances: Studies in the Internal Structure of Categories." Cognitive Pscyhology 7: 573605.

Schelling, Thomas C. 1960. The Strategy of Conflict. Cambridge, MA: Harvard University Press.

Smith, Barbara Herrnstein. 1983. "Contingencies of Value." Critical Inquiry 10(1): 1-35.

Sugden, Robert. 1995. "A Theory of Focal Points." The Economic Journal 105(430): 533-550.

Weber, Max. 1904 [1949]. The Methodology of the Social Sciences, edited by Edward A. Shills and Henry A. Finch. Glencoe, IL: The Free Press.

White, Harrison C. 2002. Markets from Networks: Socioeconomic Models of Production. Princeton, NJ: Princeton University Press.

Wilson, Elliott. 2012. "Believe the Kendrick Lamar Hype?" Life and Times, http://lifeandtimes.com/believe-the-kendrick-lamar-hype, accessed June 8, 2016.

Zuckerman, Ezra W. 1999. "The Categorical Imperative: Securities Analysts and the Illegitimacy Discount." American Journal of Sociology 104(5): 1398-1438. 


\section{Valuation Studies}

Erwin Dekker is assistant professor in cultural economics at the Erasmus University in Rotterdam, and post-doctoral fellow at the George Mason University Department of Economics. He has recently published The Viennese Students of Civilization with Cambridge University Press. His research focuses on every area where art and culture meet economics. He has published in the fields of cultural economics, economic methodology and intellectual history, and he is currently working on exemplary goods and moral frameworks. Previously he has worked as lecturer at the European Studies department at the University of Amsterdam, where he specialized in political economy. 